\title{
Valve-sparing aortic root replacement after double-switch operation for corrected transposition of the great arteries in a patient with ulcerative colitis
}

Toshihito Gomibuchi, MD, ${ }^{\mathrm{a}}$ Kenji Okada, MD, ${ }^{\mathrm{a}}$ Tatsuichiro Seto, MD, ${ }^{\mathrm{a}}$ and Yutaka Okita, MD, ${ }^{\mathrm{b}}$ Matsumoto and Kobe, Japan

From the a Division of Cardiovascular Surgery, Department of Surgery, Shinshu University School of Medicine, Matsumoto, Japan; and the ${ }^{\mathrm{b}}$ Division of Cardiovascular Surgery, Department of Surgery, Kobe University Graduate School of Medicine, Kobe, Japan.

Disclosures: Authors have nothing to disclose with regard to commercial support.

Received for publication Nov 5, 2017; revisions received Dec 18, 2017; accepted for publication Jan 8, 2018; available ahead of print March 3, 2018

Address for reprints: Kenji Okada, MD, Department of Cardiovascular Surgery, Shinshu University School of Medicine, Asahi 3-1-1, Matsumoto, Nagano 390-8621, Japan (E-mail: keokada@shinshu-u.ac.jp).

J Thorac Cardiovasc Surg 2018; 155:e175-6

$0022-5223 / \$ 36.00$

Copyright (C) 2018 by The American Association for Thoracic Surgery

https://doi.org/10.1016/j.jtcvs.2018.01.071

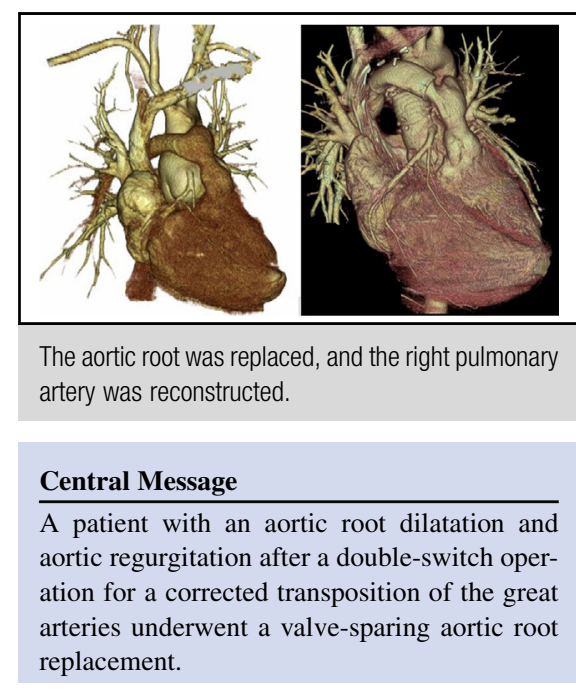

See Editorial Commentary page e177.
The outcomes of a double-switch operation for a corrected transposition of the great arteries (cTGA) have improved dramatically during the past decade, with advances in surgical techniques and perioperative care. ${ }^{1}$ Long-term studies, however, have highlighted the late development of aortic root dilation accompanied by aortic regurgitation (AR). ${ }^{2}$ We report a case of a valve-sparing aortic root replacement after a double-switch operation for cTGA in a patient with melena caused by ulcerative colitis (UC). This case report was approved by the institutional review board of Shinshu University School of Medicine (Permission No. 38912017).

\section{CLINICAL SUMMARY}

A 27-year-old man had a diagnosis of cTGA, ventricular septal defect, Ebstein anomaly, tricuspid regurgitation, and patent foramen ovale. At 5 years of age, he had undergone pulmonary artery banding for training of the left ventricle for a massive tricuspid regurgitation and also a doubleswitch operation (Senning and Jatene), Lecompte procedure, direct ventricular septal defect closure, and Reed annuloplasty of the tricuspid valve after 3 months. He had ventricular fibrillation occur while he was working 21 years later; this was followed by the implantation of a subcutaneous implantable cardioverter-defibrillator. Transthoracic echocardiography showed a severe AR with annuloaortic ectasia and an enlarged left ventricle (left ventricular end-diastolic dimension of $56 \mathrm{~mm}$, end-systolic dimension of $42 \mathrm{~mm}$, and ejection fraction of $50 \%$; Figure 1). Transesophageal echocardiography revealed the aortic valve to be tricuspid. The aortoventricular junction was $26 \mathrm{~mm}$ in diameter, the sinus of Valsalva was $51 \mathrm{~mm}$, and the sinotubular junction was $35 \mathrm{~mm}$. Coronary angiography appeared normal. The patient had had UC diagnosed 4 years previously, and since then he had had repeated progression and remission accompanied by melena.

We performed a median resternotomy, and cardiopulmonary bypass was established with ascending aorta and bicaval cannulations. The ascending aorta was crossclamped, and the right pulmonary artery was transected to secure a field of operative view. The aortic valve consisted of the largest cusp (left cardiac cusp), the second largest cusp (noncoronary cusp), and the smaller cusp (right coronary cusp). The aortoventricular junction was $25 \mathrm{~mm}$ in diameter. A valvesparing aortic root replacement with a reimplantation technique was applied. The aortic root was replaced with a 28-mm Valsalva graft (Gelweave Valsalva graft; Terumo Medical, Somerset, NJ) with 12 reinforced 3-0 polyester (Nespolene; Alfresa Pharma Co, Osaka, Japan) mattress sutures in the first row. The second row of 5-0 polypropylene continuous sutures was placed starting at the bottom of 


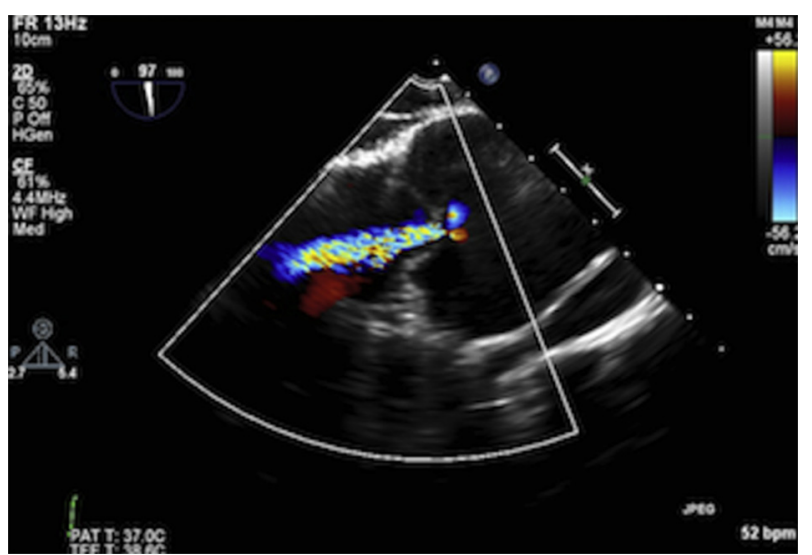

FIGURE 1. Preoperative transesophageal echocardiography showing a root dilation and severe aortic regurgitation.

each sinus and sewing upward to each commissure to create a crescent shape. Valve competency were assessed intraoperatively by applying pressure of $250 \mathrm{~mm} \mathrm{Hg}$ to the Valsalva graft with a cardioplegic solution. After completion of right and left coronary anastomoses, the ascending aorta was replaced with a 24-mm unibranch aortic graft (Triplex; Terumo Medical). The right pulmonary artery was reconstructed with a 16-mm GORE-TEX graft (W. L. Gore \& Associates, Flagstaff, Ariz). The patient was easily weaned from cardiopulmonary bypass, and an intraoperative transesophageal echocardiography did not show AR (Video 1). Cardiopulmonary bypass and myocardial ischemia times were 202 minutes and 162 minutes, respectively. The postoperative course was uneventful, and the patient was doing well 3 months after surgery without any recurrence of AR.

\section{DISCUSSION}

Improved surgical treatments for congenital heart disease have led to an increase in surgical cases of adult congenital heart disease. Aortic root dilation and AR may progress after an arterial switch operation for cTGA. Marcy and colleagues ${ }^{2}$ reported that the probability of freedom from an aortic root dilation at 10 years was $51 \%$; freedom from at least moderate AR was $93 \%$, and freedom from aortic valve or root surgery was $95 \%$. If surgical repair is required, an aortic root replacement with a composite mechanical valve graft (mechanical Bentall procedure) is performed, and the patient receives long-term anticoagulation. The current patient had UC with sporadic melena, however, so an anticoagulant medication was contraindicated. In a systematic

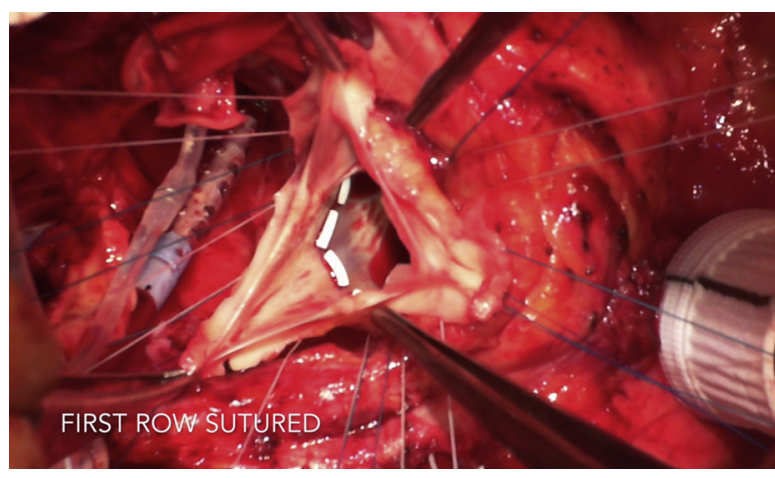

VIDEO 1. Valve-sparing aortic root replacement after a double-switch operation for a corrected transposition of the great arteries. Video available at: http://www.jtcvsonline.org/article/S0022-5223(18)30334-9/fulltext.

review and meta-analysis, rates of late hemorrhage were substantially lower after a valve-sparing aortic root replacement than with the mechanical Bentall procedure. ${ }^{3}$ An aortic valve-sparing reimplantation has been demonstrated to be an effective treatment for aortic root dilation and AR after cTGA, although the total number of cases presented remains small, and the follow-up period is still relatively short. ${ }^{4}$ In cases of valve-sparing autograft reoperations after a Ross procedure, freedom from reintervention was $76 \%$ at 8 years, with acceptable reintervention rates. ${ }^{5}$ We therefore chose a valve-sparing aortic root replacement procedure for this patient.

In conclusion, valve-sparing root replacement after a double-switch operation for cTGA was an appropriate surgical technique for a patient with UC.

\section{References}

1. Committee for Scientific Affairs, The Japanese Association for Thoracic Surgery, Masuda M, Okumura M, Doki Y, Endo S, Hirata Y, Kobayashi J, et al. Thoracic and cardiovascular surgery in Japan during 2014: annual report by The Japanese Association for Thoracic Surgery. Gen Thorac Cardiovasc Surg. 2016;64:665-97.

2. Schwartz ML, Gauvreau K, del Nido P, Mayer JE, Colan SD. Long-term predictors of aortic root dilation and aortic regurgitation after arterial switch operation. Circulation. 2004;110(11 Suppl 1):II128-32.

3. Mookhoek A, Korteland NM, Arabkhani B, Di Centa I, Lansac E, Bekkers JA, et al. Bentall procedure: a systematic review and meta-analysis. Ann Thorac Surg. 2016;101:1684-9.

4. Baliulis G, Ropponen JO, Salmon TP, Kaarne MO. Valve-sparing aortic root replacement in adult patients previously operated for congenital heart defects: an initial experience. Eur J Cardiothorac Surg. 2016;50:155-9.

5. Mookhoek A, de Kerchove L, El Khoury G, Weimar T, Luciani GB, Mazzucco A, et al. European multicenter experience with valve-sparing reoperations after the Ross procedure. J Thorac Cardiovasc Surg. 2015;150: $1132-7$. 